EESTI NSV TEADUSTE AKADEEMIA TOIMETISED. 19. KÖIDE

KEEMIA * GEOLOOGIA. 1970, NR. 3

ИЗВЕСТИЯ АКАДЕМИИ НАУК ЭСТОНСКОН ССР. ТОМ 19

ХИМИЯ * ГЕОЛОГИЯ. 1970, № 3

H. ХЕИНСАЛУ

\title{
ОСОБЕННОСТИ СТРОЕНИЯ И РАЗВИТИЯ КАРСТОВОГО УЧАСТКА УХАКУ В СЕВЕРО-ВОСТОЧНОЙ ЭСТОНИИ
}

Қарстовый участок Ухаку расположен на Северо-Эстонском плато недалеко от пос. Люганузе и является самым крупным в Северо-Восточ-

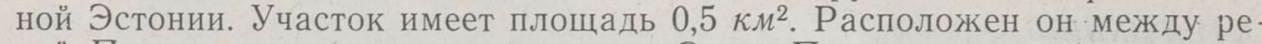
кой Пуртсе и ее западным притоком Эрра. Последняя, приближаясь к реке Пуртсе, теряет свою воду в многочисленных карстовых воронках, развитых вдоль русла реки на расстоянии $1-2 \kappa м$ от ее устья. Воронки поглощают воду со скоростью более $300 \Omega / c е \kappa$. Ниже русло р. Эрра является обычно сухим. Кратковременный поток появляется в нем только во время весеннего половодья и после обильных затяжных дождей, когда поноры не могут поглотить всю воду. Речные воды текут по подземным путям в сторону р. Пуртсе и выходят в ее долину в виде многочисленных источников. Расстояние между понорами и карстовыми источниками достигает при этом 0,4-2,0 км, а различие в высоте уровней вышеназванных рек - $1-5 м$.

Первые сведения о подземной реке и карстовых воронках Ухаку приведены уже в литературе XVIII столетия (Hupel, 1777). Отмечается, что около Люганузе река на протяжении 0,5 км течет под землей и на полях имеются большие глубокие ямы. Эти «земляные воронки» отмечены даже в географическом атласе Л. Меллина (1798). Во второй половине ХІХ стслетия некоторые исследователи приводят уже краткие данные о размерах понор и воронок карстового участка (Eichwald, 1854; Schmidt, 1858; Шмидт, 1879). Первые описания карстового участка являются краеведческими и относятся к 20-м годам нынешнего столетия (Vilberg, 1921; Erde, 1924). Первая геологическая характеристика карстового участка дана К. Орвику (1929). Им подчеркивается большое значение литологического характера, падения слоев и трещин в развитии карста. По возрасту карст относится к доледниковому времени. Карстовый участок предлагается взять под охрану природы (Orviku, 1940).

Қарст в Ухаку развит в основном в нижней части ухакуского горизонта $\left(\mathrm{O}_{2}\right.$ цh), который отличается здесь от остальных карбонатных пород ордовика своей глинистостью и является относительным водоупором в Северо-Восточной Эстонии. Горизонт представлен более или менее глинистыми тонкослоистыми известняками с частыми прослойками мергеля мощностью в $1-2$ см.

Содержание нерастворимого остатка известняков ухакуского горизонта колеблется в пределах 6-40\%. В нижней части горизонта содержание его в среднем составляет $10 \%$. Ниже ухакуского горизонта залегают весьма чистые извесгняки ласнамягиского горизонта $\left(\mathrm{O}_{2} \mathrm{~lm}\right)$, глубина кровли которых в районе карстового участка около 5-6 
ные породы покрыты четвертичными отложениями: мореной мощностью до $0,1-0,3$ м и залегающими на ней флювиогляциальными песками мощностью в $1-1,5 \mu$.

Карстующаяся толща имеет незначительный уклон (15') в южном направлении. Она разбита частыми тектоническими трещинами, имеющими северо-западное, северо-восточное, субмеридиональное или субширотное простирание; расстояние между ними порядка $0,2-2$ м. Трещины почти вертикальные и многие из них пересекают всю видимую мощность карстующейся толщи. Длина трещин, судя по размерам цепей

Рис. 1. Роза-диаграмма тектонической трещиноватости об. нажения р. Пуртсе в районе карстовых источников Ухаку.

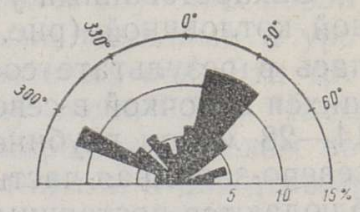

карстовых воронок, доходит до нескольких десятков, а иногда и до 200 300 м. Наиболее частыми являются трещины северо-западного и северовосточного простирания (рис. 1). Но в развитии карста и долин видную роль играли только трещины северо-западного и субмеридионального простирання (рис. 2). На это указывают хорошо выраженные прямые участки русла реки северозападного простирания, частое расположение на участке карстовых воронок и понор, вытянутых в северо-западном направлении, а также цепи воронок этого же направления между рр. Эрра и Пуртсе. Эти трещины образуют в пределах карстового участка четыре локальные зоны, отстоящие друг от друга на $150-200$ м и шириной до 300 м

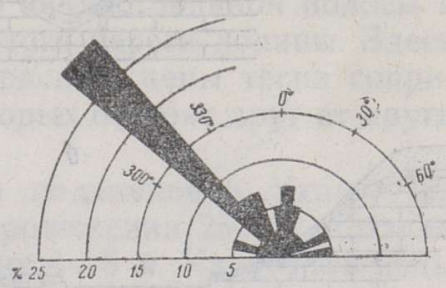

Рис. 2. Роза-диаграмма азимутов простирания больших осей карстовых воронок и их цепей на карстовом участке Ухаку. (рис. 3). По зонам трещин развиты группы понор и параллельные цепи карстовых воронок. По-видимому, в каждой такой зоне имеются $1-4$ основные трещины сравнительно большой протяженности и ряд параллельных и коротких трещин, расположенных кулисообразно.

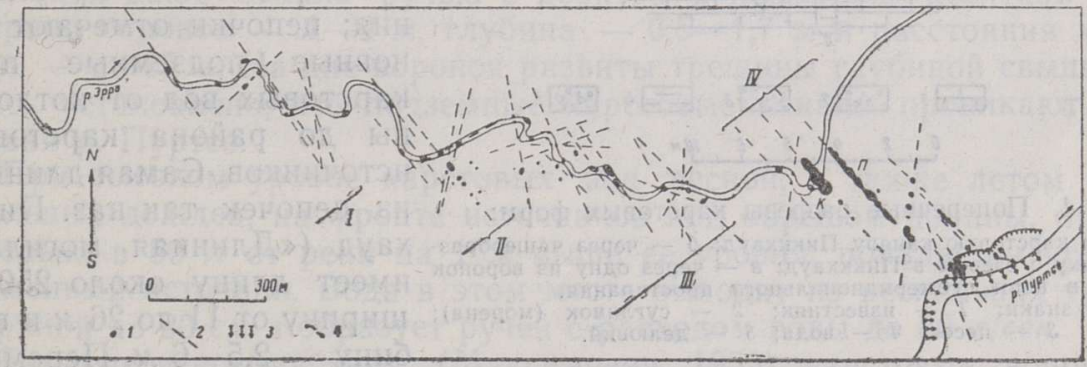

Рис. 3. Схематическая карта карстового участка Ухаку:

1 - карстовые воронки; 2 - тектонические трещины; 3 - фронт источников; 4 - ру чьи карстовых родниковых вод; $K$ - карстовая котловина; $\Pi$ - карстовая канава Пиккхауд; I-IV - закарстованные зоны трещин.

Поверхностные карстовые формы на участке Ухаку выражены в виде карстовых воронок и их цепей. Воронки вдоль русла р. Эрра расположены обычно посередине русла, образуя расширения овальной формы. Диаметр большинства воронок доходит здесь до $20-30$ м, а глубина -

5 ENSV TA Toimetised $\mathrm{K} * \mathrm{G}-31970$ 
$0,5-2,0$ м. Нормальная ширина русла реки около 10 м и глубина 0,5-1,0 . Большая ось этих расширений вытянута чаще всего в северо западном направлении. Небольшие карстовые воронки и поноры встречаются еще на борту русла реки. Их ширина доходит до $4 \mathcal{M}$ и глубина до 1 м. Иногда они имеют связь с руслом реки только через узкий канал длиною в несколько метров. В ряде мест по обе стороны русла реки наблюдаются воронки или поноры продолговатой формы, имеющие обычно северо-западное простирание. Их большие оси часто совпадают, т. е. они развиты вдоль трещин, пересекающих русло реки.

Закарстованный участок р. Эрра заканчивается коррозионно-эрозионной котловиной (рис. $3, K$ ). Далее долина сухая. Котловина образова. лась в результате соединения шести карстовых воронок, располагавшихся цепочкой в северо-западном простирании. Длина ее 120 м, ширина $14-28$ м при глубине 4,5 м в наиболее глубокой юго-восточной части; северо-западная часть заилена. На дне трех более глубоких воронок наблюдаются постоянные озерки, уровень воды в которых различен.
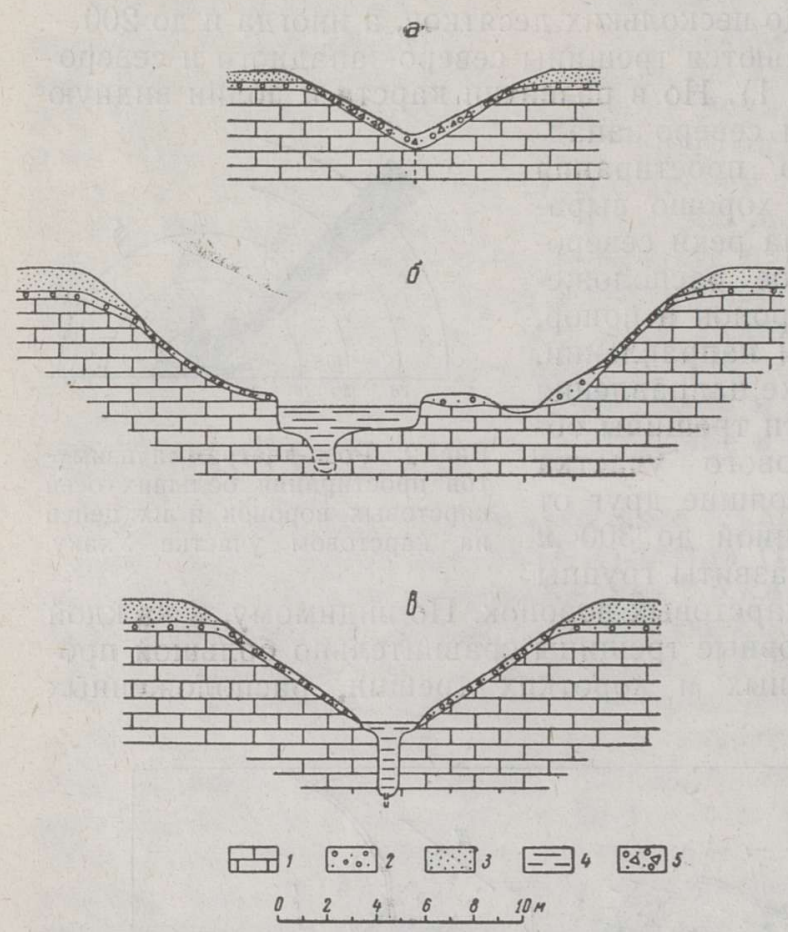

Рис. 4. Поперечные разрезы карстовых форм:

$a$ - через карстовую канаву Пиккхауд; $\sigma$ - через чашеобразную воронку с озером в Пиккхауд; в- через одну из воронок в цепи субмеридионального простирания.

Условные знаки: 1 - известняк; 2 - суглинок (морена); 3 - песок; 4- вода; 5 - делювий. ронками в этой цепочке размыты эрозией и суффозионно-карстовыми процессами, что дает ему канавообразный вид. Профиль этой цепочки воронок $V$-образный (рис. $4, a$ ), за исключением трех наиболее глубоких и широких мест, где воронки чашеобразные, с шириной дна до 10 м (рис. 4,6$)$. Крутизна склонов Пиккхауд - 22-60․ В некоторых воронках в Пиккхауд происходит поглощение воды, которая течет сюда при высоком уровне р. Эрра.

Карстовые воронки между долинами рек также приурочены к зонам тре: щин. Воронки, связанные с зонами трещин I-III, имеют конусообразную форму и развиты только вблизи р. Эрра. Диаметр их достигает $15 \mu$, а глубина $0,5-2,5$ м. Местами эти воронки (вместе с воронками в русле реки) образуют цепочки северо-западного простирания.

IV зона трещин сильно закарстована, особенно в прибортовой части долины р. Пуртсе. По этой зоне воронки образуют три цепочки северо-западного и одну субширотного простирания; цепочки отмечают основные подземные пути карстовых вод от котловины до района карстовых источников. Самая длинная из цепочек так наз. Пиккхауд («Длинная могила») имеет длину около $250 \mathrm{~m}$, ширину от 11 до 26 м и глубину - 2,5-6 м. Перемычки между отдельными во- 
B IV зоне трещин имеется цепь из шести карстовых воронок субши ротного простирания. Четыре из них большие, конусовидные (рис, 4, в), имеющие в плане овальную, крестовидную или треугольную форму, вытянуты в основном в северо-западном или субширотном направлении. Из этого следует, что некоторые из них развивались на местах пересечения трещин разного направления. Длина этих воронок достигает 65 м, ширина $-17-30$ м и глубина $-4,5-5,5 м$ при крутизне склонов $22-40^{\circ}$. Дно воронок имеет ширину $1-3$ м.

В некоторых карстовых воронках этой цепочки, а также в Пиккхауд находятся озерки глубиной в $0,5-4,0$ м. Озерки в более глубоких воронках связаны через трещины подземными карстовыми каналами и уровень воды в них отражает зеркало подземных карстовых вод. Эти трещины имеют местами глубину свыше 2 и ширину около $0,3 \boldsymbol{\mu}$. Часть маленьких озерков находится в заиленных и закупоренных маслом во. ронках глубиной в 3-4 м, питающихся весенними талыми и дождевыми водами. Уровень воды в них летом на $1-2$ м выше уровня карстовых вод.

В бровке р. Пуртсе в пределах IV зоны трещин имеется группа конусовидных воронок с верхним диаметром 5-10 м, нижним диаметром $0,5-1,0$ и и глубиной до 5 м. Ширина сильно закарстованной полосы в бровке доходит здесь до. 50 м, начиная от крутого берега долины. Здесь выделяется участок размером $30 \times 30$ м, где расположены тесно соприкасающиеся между собой воронки, центры которых отстоят друг от друга всего на $5-10$ м.

B IV зоне трещин находятся и источники подземной р. Ухаку. Иж. фронт идет по левому берегу р. Пуртсе на протяжении $250 \mu$. Долина реки имеет в этом месте относительную глубину $4-5 \mu$. Карстовые воды выходят из многих трещин шириной в 0,5-5,0 cм, расположенных на подножии обрывистого склона долины, а также на дне русла реки в виде восходящих родников, хорошо наблюдаемых в период межени, когда глубина воды в реке всего $0,3-0,5$ м. Трещин-источников более 10 , при том они расположены в $1-20$ м друг от друга. Во время низкого уровня воды в р. Пуртсе из некоторых источников вода бьет фонтаном, поднимаясь выше поверхности земли или реки до $10 \mathrm{~cm}$.

На фронте имеется 4 карстовых озерка-источника. Они расположены на террасе, в 60 м от русла реки и приблизительно на $1 \mathcal{M}$ выше ее уровня, и дают начало ручью с дебитом в несколько десятков $\Omega / c e \kappa$. Ширина воронок - $4-9$ м, глубина - 0,5-1,7 $м$ и расстояния между ними - до $15 м$. На дне воронок развиты трещины глубиной свыше $2 \mu$. Здесь установлено, что подземные карстовые каналы проникают ниже уровня р. Пуртсе.

При высоком уровне карстовых вод весной, а также летом после обильных дождей, на фронте источников под обрывом долины, приблизительно в 50 м от реки на $1 \mathcal{M}$ выше ее уровня, появляется крупный временный источник. Вода в этом месте выходит из нескольких трещин шириной до 20 см и образует ручей с расходом воды до 50 л/сек.

По генетическому типу (Максимович, 1953) карстовые воронки в Ухаку являются в основном коррозионно-эрозионными или коррозионно. провальными. Эрозионный процесс сыграл большую роль в развитии воронок и котловины в русле р. Әрра, карстовой канавы Іиккхауд, а также источниковых воронок. Этому развитию способствовала сильная глини стость известняков. Воронки между долинами образовались в результате мелких провалов карстовых полостей, поверхностного и подземного смыва четвертичных отложений, а также глинистых прослоев карстующихся пород через трещины и поноры в подземные карстовые полости, 
Имеющиеся данные по морфологии и геологическому строению не указывают на то, что они образовались в результате крупных провалов. Согласно наблюдениям, проведенным нами в течение последних 20 -ти лет, развитие воронок начинается здесь с образования провала шириной и глубиной лишь в $1-2$ м. За это время произошло три таких провала.

В дальнейшем стенки провала становятся пологими и конусовидными. Глубина и ширина воронки увеличиваются в основном благодаря коррозионным и суффозионным процессам и мелким провалам в ее центре. Провальный процесс идет при этом постепенно в виде выпадения небольших кусков известняка из кровли карстовой полости и из стенок открытых трещин. Әто происходит по мере разрушения и сноса подземным потоком материала, свалившегося в карстовую полость. Нсключением, возможно, являются некоторые воронки глубиной в $2-3$ м, имеющие широкое плоское дно. Последнее обстоятельство указывает на то, чтс воронка могла образоваться в результате одного провала.

Данные о подземных формах карста в Ухаку являются весьма скудными. Их исследованию препятствует толстый слой густого масла на склонах воронок и его лужи на дне, оставшегося здесь от сточных вод, спускаемых в р. Эрра уже около 30 лет. Поэтому трещины и большинство понор, которые ведут в подземные каналы, наблюдениям недоступны. До загрязнения воронок такие трещины встречались в некоторых воронках (Erde, 1924), причем через трешины наблюдался подземный канал высотой в 1 м. В настоящее время карстовые полости открываются на поверхности только в двух местах. На юго-восточном конце Пиккхауд имеется вертикальная щелевидная понора шириной в $0,1-0,4$ м и высотой 1,5 $м$. Ее размеры не меняются на видимом участке, т. е. на расстоянии 3-4 $м$. Шель развита по трещине, вдоль которой образовался Пиккхауд. Такой же характер имеет другой подземный канал, на ходящийся на бровке долины р. Пуртсе, на фронте источников. Канал

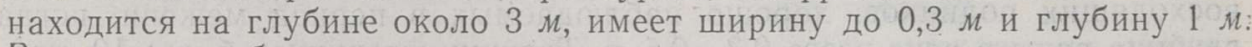
Вода течет в обоих каналах только при высоком уровне карстовых вод.

Кроме вертикальных щелевидных полостей на карстовом участке встречаются и небольшие межпластовые каналы. Например, по сведениям Г. Вильберга, в начале 20 -х годов этого столетия в карстовую котловину открывалась полость высотой в $0,25 \mu$ и шириной $2 \mu$ (Vilberg, 1921), которая была на карстовом участке самой большой. Указывается еще, что в районе источников находился маленький грот шириной до $1 \mathrm{M}$. Об этом гроте, вероятно, пишет и И. Эрде (Erde, 1924), по данным которого грот имел высоту 1,5 $\boldsymbol{м}$ и мог вместить несколько человек. Грот, повидимому, находился рядом с вышеназванным крупным временным источником в обрыве. Еще в 40-х годах здесь наблюдалась ниша глубиной около 0,5 м.

Пещеры на карстовом участке Ухаку не обнаружены. По-видимому, из-за глинистости карстующихся пород, густой сети трещин и неглубокого залегания, более крупные карстовые полости здесь сохраниться не могут. Подземные формы карста представлены только в виде узких и невысоких каналов, развитых по тектоническим трещинам северо-западного и субмеридионального простирания или по напластованию. В связи с этим трудно согласиться с некоторыми авторами (Pabst, 1873; Фальковский, 1947 и др.), по мнению которых именно на карстовом участке Ухаку находились пещеры, которые служили населению убежищем во время военного похода новгородцев в 1268 году в Северную Эстонию (Новгородская первая летопись старшего и младшего изводов, 1950). Нам кажется, что эти пещеры надо искать в обрыве глинта на побе- 
режье Финского залива, где известны суффозионные пещеры в кембрийскнх песчаниках.

Начало развития карстового участка Ухаку относится к дочетвертичному периоду, на что обратил внимание K. Орвику (Orviku, 1929). Особенно интенсивное развитие карста началось здесь, как и на всей территории Әстонской карстовой области, после образования систем трещин северо-западного и субмеридионального простирания и соответствующей системы долинной сети как местного базиса карста. Это произсшло в плейстоцене.

Базисом доплейстоценового карста была древняя долина Пуртсе, погребенная под четвертичными отложениями. Эта долина расположена на расстоянии около 1 км восточнее карстового участка и имеет относительную глубину более 90 м. На древний, более глубокий базис карста указывает то, что дно карстовых каналов ниже дна современной долины р. Пуртсе.

О характере доплейстоценового карста в Ухаку, а также карста межледниковых периодов имеется пока мало данных. На развитие карста до последнего оледенения указывают закарстованные тектонические трещины в обнажениях известняков по долине р. Пуртсе, заполненные глинистым материалом. Эти, так наз. осадочные жилы имеют мощность $1-5$ см. Их материал макроскопически не отличается от материала морены в данном месте.

На древний карст указывает также то, что нижняя часть некоторых больших карстовых воронок находится в бурых, мореноподобных суглинках, имеющих мощность более 1 м. По некоторым данным мощность этих суглинков достигает на местах, не затронутых современным карстом, 5-6 м. Бо́льшая мощность суглинков по сравнению со слоем морены около воронок $(0,2-0,5 \mu)$ и их литологический характер дает основание считать, что они за полняли древние карстовые воронки и отлагались во время последнего оледенения. На месте некоторых погребенных воронок в голоцене образовались новые, притом значительная часть этих суглинков была снесена суффозией и эрозией. Такие воронки являются доледниково-голоценовыми, а некоторые из них, возможно, частично образовались даже в доплейстоценовое время. Современные поверхностные и подземные карстовые формы, развивающиеся на базе древнего карста, начали образовываться в Ухаку после отступания Балтийского ледникового озера. Осо-

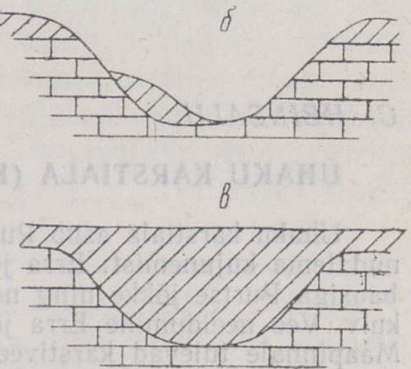

स्पा प्त2

Рис. 5. Возрастные типы карстовых воронок в Ухаку:

$a$ - голоценовый; $\sigma$ - доледни ково-голоценовый; 8 - доледни ковый (погребенный).

1 - коренные породы; 2 - гля циальные отложения. бенно интенсивно карст развивался здесь в последние тысячелетия, когда долины рек углублялись в коренные породы и увеличивалась разница уровней их врезания. Таким образом, по возрасту на карстовом участке можно выделить доледниковые (погребенные), доледниково-голоценовые и голоце новые воронки (рис. 5), а в развитии участка - доплейстоценовый, плейстоценовый и голоценовый этапы развития. 


\section{Л И Т Е Р А Т Р Р}

Макси м ович Г. А. 1953. Генетические тилы карстовых образований. ДАН СССР, 90, № 6.

Новгородская первая летопись старшего и младшего изводов. 1950. Ин-т истории AH CCCP

Ш мидт Ф. Б. 1879. Протокол заседания отделения геологии и минералогии 23 ноября 1878 г. Научное сообщение. Тр. С.-Петербургского об-ва естествоиспытателей, X, С.-Петербург.

Ф а л ь ко в С к и й Н. И. 1947. История водоснабжения в России. Изд. Мин. коммунальн. хоз-ва.

Eichwald E. 1854. Die Grauwackenschichten von Liv- und Ehstland. Bull. de la Soc. Imp. des Natural. de Moscou, XXVII, Nr. 1.

E r d e J. 1924. Maa-alune jōgi Uhak Lüganusel. Virumaa. Rakvere.

He ins a l u U. 1961. Karstinähtuste levik ja omapära Eestis. ENSV TA Geol. Inst. Uurimused, VII.

Hupel A W. 1777. Topographische Nachrichten von Lief- und Ehstland. Nachtrag zum ersten Bande.

Me 11 in L. 1798. Lief-Estländischer Atlas.

O r vi k u K. 1929. Uhaku. Kirde-Eesti karstiala stratigraafiast ja geomorfoloogiast. Tartu.

O rviku K. 1940. Uhaku karstiala looduskaitse alana. Tartu Ulik. Geol.-inst. Toimet., 59.

P a b st E. 1873. Die Russenschlacht bei Maholm im Jahre 1268, nicht von Plettenberg 1501 geliefert. Beiträge zur Kunde Ehst-, Liv- und Kurlands, 1, Reval.

$\mathrm{Schmidt}$ Fr. 1858. Untersuchungen über die silurische Formation von Ehstland, NordLivland und Oesel. Archiv f. d. Naturkunde Liv-, Ehst- und Kurlands, Ser. I, 2, Dorpat.

V ilberg G. 1921. Salajōed ja maa-alused koopad Eestis. «Sirvilaudade» XXV juubeliaasta lisa.

Ннститут геологии
Академии наук Эстонгкой ССР

Поступила в редактию

$5 / \mathrm{I} \quad 1970$

\section{HEINSALU}

\section{UHAKU KARSTIALA (KIRDE-EESTI) EHITUSE JA ARENGU ISEARRASUSED}

Uhaku karstiala asub Purtse jōe ja selle lisajōe Erra vahel. See asjaolu ongi mōjutanud tema kujunemist: Erra jõe veed on rajanud maa-aluse äravoolu madalama erosioonibaasiga Purtse jōkke ning nende säng on karstialast kuni suudmeni suurema osa aastast kuiv. Vee neeldumine Erra jōes toimub arvukate $1 \mathrm{~km}$ ulatuses esinevate lehtrite kaudu. Maapinnale tulevad karstiveed allikatena Purtse jõe ääres ja põhjas $250 \mathrm{~m}$ pikkusel löigul.

Karst on arenenud uhaku ja lasnamäe lademe lubjakivides $\left(\mathrm{O}_{2}\right.$ uh, $\left.\mathrm{lm}\right)$, milledest esimesed on savikad, eriti sagedaste merglivahekihikestega. Karsti kujunemist on soodustanud tihe tektooniliste lōhede vōrk, kusjuures kōige suurem on olnud loode-kagusuunaliste lõhesüsteemide tähtsus. Need lōhed moodustavad karstialal neli lokaalset vööndit, milledele vastavalt on kujunenud ka ponooride rühmad ja karstilehtrite ahelad. Esineb ka üks submeridionaalse suunaga lehtrite ahel. Uksikute lehtrite pikiteljed on enamasti loode-kag'1suunalised.

Lehtrite pikkus ulatub karstialal 65 , laius 30 ja sügavus 6 meetrini. Lehtrite ahela pikkus on kuni $250 \mathrm{~m}$. Ristlõikes on lehtrid enamasti koonusjad, harvem liudjad. Valdab korrosiooni-erosiooni- või korrosiooni-sisselangemislehtrite tüüp, kusjuures karstivormide kujunemises on oluline olnud erosiooni osatähtsus.

Maa-alused karstikanalid on kitsad püstlōhed vōi madalad ja laiad kihtidevahelised õõnsused. Koopaid ei ole.

Uhaku karstiala esines juba jääajaeelsel ajal. Jääajajärgsel kontinentaalsel perioodil tekkisid siin uued pindmised karstivormid, milledest osa asub mandrijää setete alla mattınud vanade karstilehtrite kohal. Karstiala arengus võib esile tõsta pleistotseenieelset, pleistotseeni- ja holotseenietappi. 


\section{U. HEINSALU}

\section{THE STRUCTURE AND PECULIARITIES OF THE UHAKU CARST AREA IN THE NE OF ESTONIA}

The Uhaku carst area lies between the river of Purtse and its tributary, the Erra. That circumstance has determined the nature of that area: the waters of the Erra have established their underground drainage into the Purtse, which is of a lower erosional basis, and the river-bed proper of the Erra, from the carst area to the estuary, is dry most part of the year. The absorption of the waters in the Erra is effected through numerous funnels which are situated on a stretch of $1 \mathrm{~km}$. The carst waters come up to the surface of the earth by way of springs at the riverside of the Purtse, and in the bottom of that river, on a stretch of $250 \mathrm{~m}$.

The carst has developed in the limestones of the Uhaku and Lasnamäe stages $\left(\mathrm{O}_{2}\right.$ uh, $\mathrm{lm})$, the former of which are clayey, with particularly frequent marl-interlaminations. The development of the carst has been favoured by a dense network of tectonic faults, the most significant of which are of a NW-SE orientation. In the carst area those faults form four local zones, according to which the groups of ponors and chains of carst funnels have been formed. There is also a chain of funnels of a submeridional orientation present. The longitudinal axis of some single funnels are oriented from NW to SE.

The length of single funnels in the carst area amounts to $65 \mathrm{~m}$, width to $30 \mathrm{~m}$, and depth to $6 \mathrm{~m}$. The chain of funnels is about $250 \mathrm{~m}$ long. In cross-section, the funnels are mostly of a conical shape, and less frequently dish-shaped. The prevailing types are corrosional-erosional or corrosional-collapsing, since an important role in the formation of the carst was enacted by, erosion.

The underground carst canals are narrow upright cracks or shallow and wide hollows between strata. There are no carst caves present.

The carst area of Uhaku existed already in the pre-glacial period. In the continental post-glacial period, the surface carst forms developed, the majority of which are situated in the place of old carst funnels, buried under the deposits of continental ice. In the development of the area we may state the pre-Pleistocene, Pleistocene and Holocene stages. 